than $10 \%$ of arterial oxygen tension is derived from the inflow cannula. This evidence rules out clinically relevant recirculation volume. ${ }^{4}$ However, limited effective interventions could improve oxygen delivery. Relocating the inflow cannula to the main pulmonary artery by a surgical approach was reported by our team. ${ }^{5}$ Surgical invasiveness remains a concern. Therefore, we developed this minimally invasive approach to manipulate the inflow cannula to redirect the flow and avoid mixing.

The inflow jet toward the right ventricle limits the recirculation by diversion of flow direction and reduction of mixing oxygenated and deoxygenated blood inside the right atrium or vena cavae. The depth of insertion should be estimated in advance. Plain chest radiography should offer sufficient information on the length and desired curvature. Current digital films allow us to measure the exact distance between 2 points on the screen. The curvature was only apparent inside the right atrium. The portion of cannula inside the innominate vein and superior vena cava did not allow for bending. Therefore, the turning points for the suture to stop are mainly located over the proximal third of the inserted length. The monofilament stitch was favorable for this application because of less possibility of infection. However, braided sutures such as Ethibond Excel (Ethicon, Somerville, NJ) have better strength. Once the cannula was inserted, the proper location was evaluated by arterial blood gas, chest films, and transthoracic or transesophageal echocardiography. By turning the cannula and pulling the thread to bend the tip toward the tricuspid valve, minimal recirculation was achieved. By sampling the oxygen saturation of both inflow and outflow cannulae, the proper location was determined without difficulty.

Some might be concerned about the risk of arrhythmia. Care should be given to avoid the jet irritation of the right ventricle. If arrhythmia occurs, readjustment under echocardiographic guidance should be done. The practice of manipulating the endovascular devices is common with interventionists and cardiovascular surgeons.

\section{CONCLUSIONS}

We have introduced a simple bedside maneuver of manipulating the inflow cannula of VV-ECMO to significantly reduce recirculation and increase systemic oxygen saturation. Percutaneous, tailor-made, malleable cannula may be available in the near future. Then, the troublesome issue could be reduced to the minimal extent.

\section{References}

1. Ichiba S, Peek GJ, Sosnowski AW, Brennan KJ, Firmin RK. Modifying a venovenous extracorporeal membrane oxygenation circuit to reduce recirculation. Ann Thorac Surg. 2000;69:298-9.

2. Rich PB, Awad SS, Crotti S, Hirschl RB, Bartlett RH, Schreiner RJ. A prospective comparison of atrio-femoral and femoro-atrial flow in adult venovenous extracorporeal life support. J Thorac Cardiovasc Surg. 1998;116:628-32.

3. Darling EM, Crowell T, Searles BE. Use of dilutional ultrasound monitoring to detect changes in recirculation during venovenous extracorporeal membrane oxygenation in swine. ASAIO J. 2006;52:522-4.

4. Locker GJ, Losert H, Schellongowski P, Thalhammer F, Knapp S, et al. Bedside exclusion of clinically significant recirculation volume during venovenous ECMO using conventional blood gas analyses. J Clin Anesth. 2003;15:441-5.

5. Chiu KM, Li SJ, Hung FM, Chu SH, Lin TY. Right heart bypass for acute traumatic respiratory distress syndrome. ASAIO J. 2005;51:826-8.

\title{
A workbench to make artificial chordal loops for mitral valve repair
}

\author{
Toshihiko Shibata, MD, ${ }^{a}$ Kazushige Inoue, MD, ${ }^{\mathrm{b}}$ Takeshi Ikuta, MD, ${ }^{\mathrm{b}}$ and Yasuyuki Bito, MD, \\ Osaka and Amagasaki, Japan
}

Mitral valve repair using an expanded polytetrafluoroethylene (ePTFE; Gore-Tex, W.L. Gore and Associates, Flagstaff, AZ) chorda is a reliable method. To determine the appropriate length of artificial chorda, some experiment-

\footnotetext{
From the Division of Cardiovascular Surgery, ${ }^{\mathrm{a}}$ Osaka City General Hospital, Osaka, Japan, and the Division of Cardiovascular Surgery, ${ }^{\mathrm{b}}$ Kansai Rosai Hospital, Amagasaki, Japan.

Received for publication Jan 3, 2008; accepted for publication Jan 12, 2008; available ahead of print Sept 1, 2008.

Address for reprints: Toshihiko Shibata, MD, The Division of Cardiovascular Surgery, Osaka City General Hospital, 2-1-13, Miyakojima-hondori, Miyakojima, Osaka, 534-0021, Japan (E-mail: shibata@msic.med.osaka-cu.ac.jp).

J Thorac Cardiovasc Surg 2009;138:506-7

$0022-5223 / \$ 36.00$

Copyright (c) 2009 by The American Association for Thoracic Surgery doi:10.1016/j.jtcvs.2008.01.048
}

ing is required; thus many methods to determine the right length have been advocated. Von Oppell and Mohr demonstrated a technique using a ruler to make ePTFE loops of premeasured length. ${ }^{1}$ Here, we describe a novel loop maker for artificial chordal reconstruction.

\section{TECHNIQUE}

We developed a workbench to make artificial chordal loop for mitral valve repair (03-5425; Geister, Tuttlingen, Germany). This device consists of a metal plate with 6 small, diagonally positioned rods and 2 pledget holders (Figure 1 ). The distances between the pledget holder on the reference line and the rods ranges from 15 to $25 \mathrm{~mm}$, notched at 2-mm intervals, and from 16 to $26 \mathrm{~mm}$ when used upside 


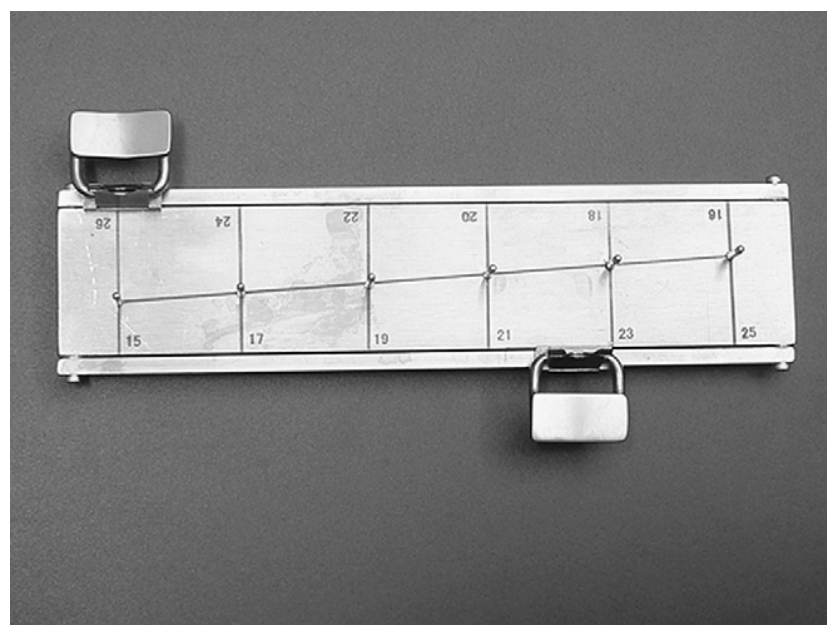

FIGURE 1. The workbench for making artificial chordal loops.

down. The pledget holder slides on the reference line. The pledget holder consists of a holder and a knob. We can open the mouth of the holder to catch the pledget by pushing the knob. The pledget holder is moved and set in the position to make ePTFE loops of the premeasured chordal length.

The ePTFE loops are produced using the technique described by von Oppell and Mohr. ${ }^{1}$ First, the pledget is fixed into the holder. An ePTFE suture (CV5) is passed through the pledget and is turned at the rod standing at the location of the desired length, and thus a loop is made. The suture is again passed through the pledget, and tied 6 to 8 times to complete the first loop. The desired number of loops is produced in the same manner (Figure 2). The pledget with ePTFE loops is taken out of the pledget holder by pushing the knob. The pledget is then trimmed to an appropriate size.

\section{DISCUSSION}

The loop technique proposed by von Oppell and Mohr is useful for complex mitral valve repairs that need numerous ePTFE chordae. There are several reports about this technique using a Mohr suture ruler (03-5409; Geister). ${ }^{2,3} \mathrm{~A}$ Mohr ruler can measure the chordal length and produce

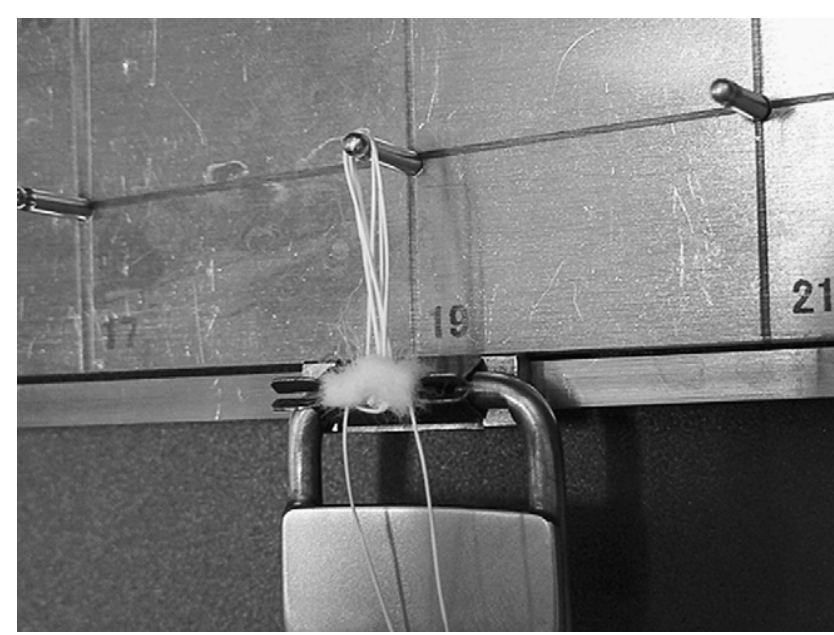

FIGURE 2. The desired number of loops are produced using a pledget fixed in the holder.

the required artificial choral loops, but it does not have a holder to catch the pledget.

We developed a workbench that has some advantages for making artificial chordal loops. The pledget holders and small rods are placed on a heavy metal board. The device enables an artificial chordal loop of an accurate length, from 15 to $26 \mathrm{~mm}$ with $1-\mathrm{mm}$ intervals, to be made by positioning the pledget holder. The holder can facilitate making tight loops of various sizes because the work base is sufficiently heavy and steady to make the loops. These advantages make it easy for a single operator to produce loops intraoperatively.

However, the device is only used to make artificial chordal loops. The length of the loop still needs to be determined by intraoperative measurement using another instrument. As well, the bench can be used to make stocks of artificial loops of various lengths preoperatively.

\section{References}

1. von Oppell UO, Mohr FW. Chordal replacement for both minimally invasive and conventional mitral valve surgery using premeasured Gore-Tex loops. Ann Thorac Surg. 2000;70:2166-8.

2. Tam R, Joshi P, Konstantinov IE. A simple method of preparing artificial chordae for mitral valve repair. J Thorac Cardiovasc Surg. 2006;132:1486-7.

3. Dang NC, Stewart AS, Kay J, Mercando ML, Kruger KH, Topkara VK, et al. Simplified placement of multiple artificial mitral valve chords. Heart Surg Forum. 2005;129-31. 